\title{
Hydrogenation of Ring-Opening Metathesis Polymer with Ruthenium Catalysts
}

\author{
Yoshinori Yoshida, Masashi Yoshinari, Akira IIO, \\ and Zen KomiYA ${ }^{\dagger}$ \\ Tsukuba Research Laboratory, JSR Corporation, \\ 25 Miyukigaoka, Tsukuba, 305-0841 Japan
}

(Received March 2, 1998)

\begin{abstract}
A ring-opening metathesis polymer (ROMP) of 8-methyl-8-methoxycarbonyltetracyclo[4.4.0.1 $\left.{ }^{2,5} .1^{7,10}\right]$ dodec3-ene (poly-1) was hydrogenated with homogeneous catalysts. Monohydrido or dihydrido ruthenium(II) complexes achieved high hydrogenation degree which gave thermally stable saturated ROMP of $\mathbf{1}$ (poly-1-H $\mathbf{H}_{2}$ ). The kinetics of hydrogenation reactions in the presence of carbonylchlorohydridotris(triphenylphosphine)ruthenium, $\mathrm{RuHCl}(\mathrm{CO})\left(\mathrm{Ph}_{3}\right)_{3},(2)$ were studied in detail and found to follow first-order kinetics to the concentration of double bonds. Apparent activation energy for the overall hydrogenation reaction determined in the temperature range of $155-180^{\circ} \mathrm{C}$ was smaller than that observed for the hydrogenation of acrylonitrile--butadiene copolymer by rhodium catalyst. The stirring rate did not affect hydrogenation reaction rate, although slower stirring lead to lower conversion at the very beginning of the reaction, indicating diffusion of hydrogen into the reaction media can be neglected if stirring is efficient. The concentration of 2 also affected the reaction rate. The reaction rate leveled off at around $3 \times 10^{-2} \mathrm{mM}$ reaching more than 4300 of turnover number. Applying $100 \mathrm{~kg} \mathrm{~cm}^{-2}$ of hydrogen at $160^{\circ} \mathrm{C}$ in $m$-xylene, high hydrogenation degrees were achieved at ruthenium concentration as low as 20 ppm to the polymer.

KEY WORDS Ring-Opening Polymerization / Metathesis / Hydrogenation / Ruthenium / Kinetics /
\end{abstract}

Ring-opening metathesis polymerization has attracted much attention for years for its unique polymerization mode. $^{1,2}$ Various types of cyclic olefins can be polymerized including monomers with polar substituent. ${ }^{3-9}$ The resultant polymer contains carbon-carbon double bond in its main chain. This has been utilized to form highly conjugated poly-ene type polymers. ${ }^{1-13}$ However, in another case, the presence of the reactive double bond deteriorates the stability of the polymer or intervenes the desired reaction of the polymer. ${ }^{14-16}$ Especially if one intends to use ring-opening metathesis polymer (ROMP)s as a thermoplastic material, the double bond needs to be saturated by hydrogenation. ${ }^{14}$ We reported that hydrogenated ROMP of 8-methyl-8methoxycarbonyltetracyclo $\left[4 \cdot 4 \cdot 0 \cdot 1^{2,5} \cdot 1^{7,10}\right]$ dodec-3-ene (1) gave thermally stable amorphous polymer with high glass transition temperature $\left(T_{\mathrm{g}}\right)$ which is suitable for optical applications. ${ }^{14}$ The thermal stability of the polymer was highly dependent on the hydrogenation degree. In the previous study, we used a heterogeneous palladium catalyst for the hydrogenation of ROMP of 1 (poly-1). Although satisfactory hydrogenation degree was obtained, the separation of the catalyst from the polymer solution was tedious because of the highly viscous polymer solution. One answer to this problem is to apply a homogeneous catalyst. If the catalyst activity is high enough to minimize the catalyst level, then separation process could potentially be eliminated.

Although various homogeneous hydrogenation catalysts are known, reports on the hydrogenation of polymers are rare. There are several reports using rhodium catalyst to hydrogenate a ROMP of dicyclopentadiene $\mathrm{1}^{16,17}$ and acrylonitrile-butadiene copolymer. ${ }^{18}$ An alternative way to hydrogenate ROMP without using metal complexes is to apply hydrazide reduction..$^{15,17,19,20}$ Such reaction requires an equimolar amount of hydrazide to double bonds, the reaction condition is mild enough for structure analyses of ROMPs. ${ }^{17,19,20}$ This paper describes the hydrogenation reactions of poly-1 with ruthenium based homogeneous catalysts. Our hope was to find catalysts with the highest activity requiring the mildest reaction conditions. Carbonylchlorohydridotris(triphenylphosphine)ruthenium, $\mathrm{RuHCl}(\mathrm{CO})\left(\mathrm{PPh}_{3}\right)_{3}(2)$ was found to be one of the most active catalysts and its kinetics of the reaction were studied.

\section{EXPERIMENTAL}

\section{Materials}

8-Methyl-8-methoxycarbonyltetracyclo[4.4.0.1 $\left.1^{2,5} \cdot 1^{7,10}\right]$ dodec-3-ene (1) and its ring opening metathesis polymer

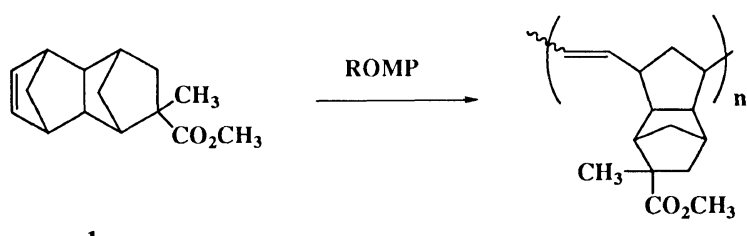

1

Poly-1

$($ cis/trans $=66 / 34)$

\footnotetext{
$\dagger$ To whom all correspondence should be addressed.
} 
Table I. Hydrogenation reactions of poly-1 with ruthenium based homogeneous catalysts ${ }^{\mathrm{a}}$

\begin{tabular}{|c|c|c|c|c|}
\hline \multirow{2}{*}{ Catalyst } & \multirow{2}{*}{ Solvent } & \multirow{2}{*}{$\begin{array}{c}\mathrm{Ru} \\
\left(\mathrm{mM} \times 10^{-2} / \mathrm{ppm}^{\mathrm{b}}\right)\end{array}$} & \multirow{2}{*}{$\frac{\text { Hydrogen pressure }}{\mathrm{kg} \mathrm{cm}^{-2}}$} & \multirow{2}{*}{$\frac{\text { Hydrogenation degree }}{\%}$} \\
\hline & & & & \\
\hline $\mathrm{RuHCl}(\mathrm{CO})\left(\mathrm{PPh}_{3}\right)_{3}(2)$ & Xylene $^{\mathrm{c}}$ & $9.89 / 100$ & 40 & 99.6 \\
\hline $\mathrm{RuHCl}(\mathrm{CO})\left(\mathrm{PPh}_{3}\right)_{3}(2)$ & Butyl acetate & $9.89 / 100$ & 40 & 99.1 \\
\hline $\mathrm{RuHCl}(\mathrm{CO})\left(\mathrm{PPh}_{3}\right)_{3}$ & THF & $9.89 / 100$ & 40 & 99.1 \\
\hline $\begin{array}{l}\mathrm{RuHCl}(\mathrm{CO})\left(\mathrm{PPh}_{3}\right)_{3}(2) \text { and } 5 \\
\text { Moles of } \mathrm{PPh}_{3}\end{array}$ & THF & $9.89 / 100$ & 40 & 94.8 \\
\hline $\mathrm{RuH}_{2}(\mathrm{CO})\left(\mathrm{PPh}_{3}\right)_{3}(3)$ & Xylene $e^{c}$ & $9.89 / 100$ & 40 & 99.4 \\
\hline $\mathrm{Ru}(\mathrm{CO})_{3}\left(\mathrm{PPh}_{3}\right)_{3}(4)$ & Xylene ${ }^{c}$ & $9.89 / 100$ & 40 & 42.8 \\
\hline $\mathrm{RuH}(\mathrm{OCOMe})(\mathrm{CO})\left(\mathrm{PPh}_{3}\right)_{3}$ & Xylene $e^{c}$ & $4.95 / 50$ & 40 & 99.8 \\
\hline $\mathrm{RuCl}_{2}\left(\mathrm{PPh}_{3}\right)_{3}(6)$ & Xylene ${ }^{\mathrm{c}}$ & $2.96 / 30$ & 40 & 67.2 \\
\hline $\mathrm{RuHCl}(\mathrm{CO})\left(\mathrm{PPh}_{3}\right)_{3}(2)$ & $m$-Xylnene & $9.89 / 100$ & 100 & $>99.9$ \\
\hline $\mathrm{RuHCl}(\mathrm{CO})\left(\mathrm{PPh}_{3}\right)_{3}(2)$ & $m$-Xylnene & $1.98 / 20$ & 100 & $>99.9$ \\
\hline
\end{tabular}

${ }^{a}$ Reaction temperature and time were $165^{\circ} \mathrm{C}$ and $4 \mathrm{~h}$ respectively. Polymer concentration was 10 wt $\%$. ${ }^{\mathrm{b}} \mathrm{Ruthenium}$ metal concentration in polymer. ${ }^{\mathrm{c}}$ Isomeric mixture was used.

(poly-1) was prepared as described in the previous paper. ${ }^{14}$

Carbonylchlorohydridotris(triphenylphosphine)ruthenium(II), $\mathrm{RuHCl}(\mathrm{CO})\left(\mathrm{PPh}_{3}\right)_{3}, \quad(2),{ }^{21}$ carbonyldihydridotris(triphenylphosphine)ruthenium(II), $\mathrm{RuH}_{2}(\mathrm{CO})\left(\mathrm{PPh}_{3}\right)_{3},(3),{ }^{21}$ tricarbonylbis(triphenylphosphine)ruthenium $(0), \mathrm{Ru}(\mathrm{CO})_{3}\left(\mathrm{PPh}_{3}\right)_{2},(4),{ }^{21}$ and carbonylhydridoacetatebis(triphenylphosphine)ruthenium(II), $\mathrm{RuH}(\mathrm{OCOMe})(\mathrm{CO})\left(\mathrm{PPh}_{3}\right)_{2},(\mathbf{5}),{ }^{22}$ were synthesized according to the literature. Dichlorotris(triphenylphosphine)ruthenium(II), $\mathrm{RuCl}_{2}\left(\mathrm{PPh}_{3}\right)_{3},(6)$, and chlorohydridotoluenetris(triphenylphosphine)ruthenium(II) $\mathrm{RuHCl}\left(\mathrm{PPh}_{3}\right)_{3} \mathrm{C}_{6} \mathrm{H}_{5} \mathrm{CH}_{3}$, (7), were purchased as commercial products and used as received.

All solvents were dried over molecular sieves (type 4A) under nitrogen.

\section{Hydrogenation}

A $100 \mathrm{ml}$ autoclave was purged with nitrogen. A ruthenium catalyst was put in the autoclave. A $10 \mathrm{wt} \%$ solution of poly-1 dissolved in a solvent was added to the vessel. After substitution of nitrogen with hydrogen, the desired pressure of hydrogen was applied and heated to the desired temperature. The mixture was reacted for $4 \mathrm{~h}$ with stirring. After the autoclave was purged with nitrogen, the reaction mixture was discharged from it. The polymer solution was poured into a large amount of methanol to separate the polymer. The white powder was dried at $80^{\circ} \mathrm{C}$ under vacuum. The degree of hydrogenation was determined by ${ }^{1} \mathrm{H}$ NMR spectrum (JEOL JNM-EX90A, $\mathrm{CDCl}_{3}$ ) of the resultant polymer by the absorption of vinyl hydrogen at $5.41 \mathrm{ppm}$ using methyl ester absorption at $3.64 \mathrm{ppm}$ as an internal standard.

Kinetic studies were carried out using a $2 \mathrm{~L}$ autoclave. The point at which hydrogen pressure was applied was defined as zero hour and the reaction mixture was heated to the desired temperature controlling the hydrogen pressure constant. Usually, it took about half an hour to reach the temperature. At constant intervals, aliquots were taken from the autoclave and hydrogenation degree was determined as described above.

\section{RESULTS AND DISCUSSION}

\section{The Catalysts}

Hydrogenation reactions of poly-1 with ruthenium complexes were carried out at $165^{\circ} \mathrm{C}$ for $4 \mathrm{~h}$ under hydrogen pressure of $40 \mathrm{~kg} \mathrm{~cm}^{-2}$. The results are summarized in Table I. High hydrogenation degree was obtained with ruthenium(II) catalysts especially hydrido and dihydrido complexes such as 2, 3, and 5. Turnover numbers were at least 4300 for these complexes. In all cases, no reduction of carboxylate group of poly-1 nor hydrogenation of xylene for solvent was observed. Hydrogenation reactions using 2 proceeded smoothly not only in aromatic solvents but also in butyl acetate and in tetrahydrofuran (THF). By using the most reactive complex, 2 , the acceptable hydrogenation degree $(>99.9 \%)$ was obtained in $4 \mathrm{~h}$ at elevated hydrogen pressure, $100 \mathrm{~kg} \mathrm{~cm}^{-2}$, in $m$-xylene. Even under vigorous conditions, no hydrogenation of the aromatic ring was observed. The ruthenium concentration could be decreased as low as $20 \mathrm{ppm}$ under the same conditions keeping high hydrogenation degree. The olefin hydrogenation reaction catalyzed by $\mathbf{2}$ has good selectivity in terminal and internal olefins and is affected by the coordinating ability of the olefin. ${ }^{23,24}$ Poly-1 consists of disubstituted cis and trans double bonds (66/34 for cis/trans), ${ }^{14}$ though no selectivity was observed. Even at low reaction conversion with small amount of $\mathbf{2}$ or at low temperature reaction, there was no indication of the selectivity between cis and trans double bond. The absence of selectivity may be attributed to the higher temperature and hydrogen pressure than those applied to the low molecular weight olefins. Additional presence of triphenylphosphine slowed the reaction as observed in previously reported cases. ${ }^{23,25}$

\section{Kinetics of the Hydrogenation of Poly-1 With 2}

Kinetics of the hydrogenation of poly-1 in the presence of the homogeneous hydrogenation catalyst $\mathbf{2}$ were investigated in $m$-xylene. All data obtained are summarized in Table II. A representative time-conversion curve is shown in Figure 1 (entry 4-2). All reactions were first order with respect to conversion of the double bond up to $99 \%$ conversion exhibiting reasonable correlation with $r^{2}$ values greater than 0.88 and yielding apparent 
Table II. Kinetic data for the hydrogenation of poly-1 with $\mathbf{2}^{\mathrm{a}}$

\begin{tabular}{|c|c|c|c|c|c|c|c|c|c|c|c|c|c|c|c|}
\hline \multirow[t]{2}{*}{ Entry } & \multirow{2}{*}{$\frac{\text { Temp }}{{ }^{\circ} \mathrm{C}}$} & \multirow{2}{*}{$\stackrel{2}{\left(\mathrm{mM} \times 10^{-2}\right)}$} & \multirow{2}{*}{$\frac{\text { Hydrogen }}{\mathrm{kg} \mathrm{cm}^{-2}}$} & \multicolumn{10}{|c|}{$\frac{\text { Time } / \mathrm{h}}{\text { Conversion } / \%}$} & \multirow{2}{*}{$\frac{k_{\mathrm{H}_{2}}}{\mathrm{~h}^{-1}}$} & \multirow[t]{2}{*}{$r^{2}$} \\
\hline & & & & 0.5 & 1.0 & 1.5 & 2.5 & 3.5 & 4.5 & 5.5 & 6.5 & 8.5 & 16.5 & & \\
\hline 1 & 180 & 9.89 & 100 & 95.3 & 98.9 & 99.8 & & $>99.9$ & $>99.9$ & & & & & 4.02 & 0.970 \\
\hline $2-1$ & 165 & 9.89 & 100 & 67.0 & 94.5 & 99.4 & 99.5 & & $>99.9$ & & $>99.9$ & & & 2.30 & 0.878 \\
\hline $2-2$ & 165 & 9.89 & 100 & 53.6 & 97.0 & 99.4 & 99.7 & & $>99.9$ & & & & & 2.53 & 0.892 \\
\hline 3 & 155 & 9.89 & 100 & 28.6 & 70.3 & 87.3 & 97.4 & & 99.8 & & $>99.9$ & $>99.9$ & & 1.43 & 0.995 \\
\hline $4-1$ & 150 & 9.89 & 100 & 36.4 & & & 94.0 & 98.3 & 99.2 & & & & & 1.11 & 0.996 \\
\hline $4-2$ & 150 & 9.89 & 100 & 36.8 & 69.5 & 83.9 & 94.9 & 98.2 & 99.4 & & & & $>99.9$ & 1.15 & 0.998 \\
\hline 5 & 140 & 9.89 & 100 & 18.4 & & & 88.9 & 97.7 & & & 99.7 & & & 0.93 & 0.983 \\
\hline 6 & 165 & 9.89 & 20 & 4.2 & & & 54.1 & & 78.6 & & & 98.2 & 99.0 & 0.31 & 0.898 \\
\hline 7 & 165 & 9.89 & 40 & 10.7 & & 66.9 & 88.7 & & 99.0 & & 99.6 & 99.6 & & 0.74 & 0.927 \\
\hline 8 & 165 & 9.89 & 70 & 22.0 & 62.7 & 87.9 & 97.7 & 99.5 & 99.6 & & 99.9 & $>99.9$ & & 1.16 & 0.944 \\
\hline 9 & 165 & 0.20 & 100 & 0 & 2.2 & 7.4 & 8.4 & 8.7 & & 12.8 & & & 21.7 & 0.014 & 0.888 \\
\hline 10 & 165 & 0.99 & 100 & 19.8 & & & & 99.5 & & & $>99.9$ & & & 1.58 & 0.991 \\
\hline 11 & 165 & 1.98 & 100 & 38.7 & 80.7 & 95.3 & 99.6 & & $>99.9$ & & $>99.9$ & & & 2.30 & 0.984 \\
\hline 12 & 165 & 19.78 & 100 & 78.2 & 96.2 & 99.1 & 99.8 & & $>99.9$ & & & & & 2.53 & 0.967 \\
\hline $13^{\mathrm{b}}$ & 165 & 9.89 & 100 & 35.5 & 83.3 & 97.9 & 99.9 & & $>99.9$ & & $>99.9$ & $>99.9$ & & 2.91 & 0.973 \\
\hline
\end{tabular}

${ }^{\mathrm{a}}[\mathrm{C}=\mathrm{C}]_{0}=0.869 \mathrm{M}, 20 \mathrm{wt} \%$ of poly-1 in $m$-xylene. ${ }^{\mathrm{b}}$ Stirring speed was lowered.

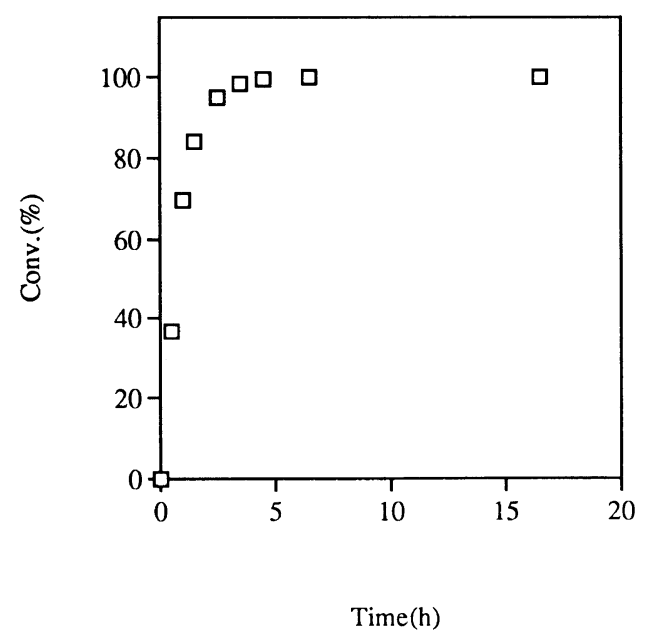

Figure 1. Time-conversion plots for entry 4-2.

hydrogenation rate, $k_{\mathrm{H}_{2}}$. One typical example is shown in Figure 2. Two sets of entries, 2-1/2-2, and 4-1/4-2 are carried out under exactly the same reaction conditions to examine the reproducibility of the experiments. As shown by $k_{\mathrm{H}_{2}}$ and $r^{2}$, good reproducibility was indicated.

The temperature of the hydrogenation reaction was varied from 140 to $180^{\circ} \mathrm{C}$ at constant pressure of hydrogen and amount of catalyst. A linear Arrhenius plot was obtained as shown in Figure 3. The apparent activation energy was calculated to be $62 \mathrm{~kJ} \mathrm{~mol}^{-1}$ which is smaller than the $\mathrm{Rh}$ catalyzed hydrogenation reaction of acrylonitrile-butadiene copolymer. ${ }^{18}$ This is surprising since poly-1 consists only of 1,2-di-substituted double bonds, whereas the acrylonitrile-butadiene copolymer contains a vinyl group which is sterically less hindered along with 1,2-di-substituted one, attributed to the absence of cyano group in poly-1 which can coordinate to the metal center and retard the hydrogenation reaction.

Low hydrogen pressure makes the commercial production of the polymer easy. Therefore lower range of hydrogen pressure was applied to the reaction as shown

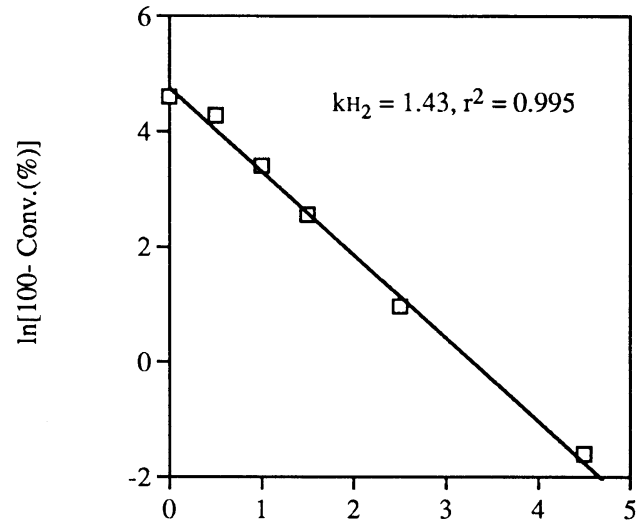

Time (h)

Figure 2. Logarithmic plots of double bond conversion with time for entry 3 indicating first order reaction.

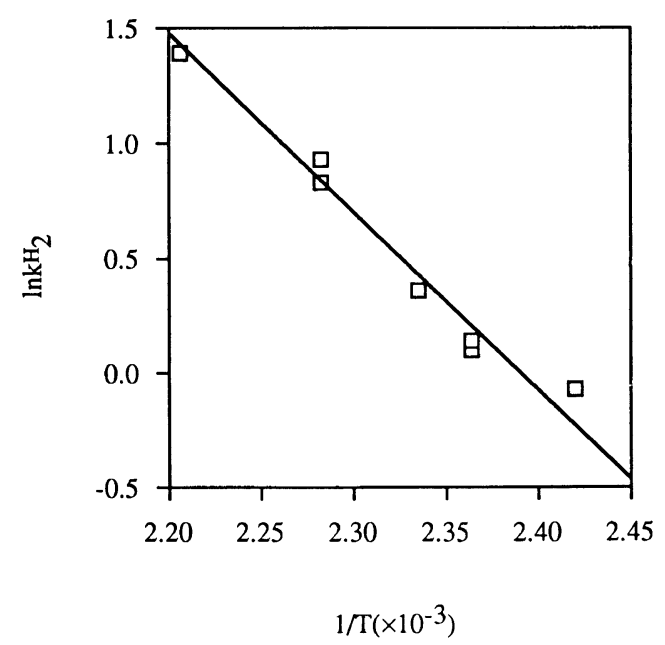

Figure 3. Arrhenius plot for the hydrogenation of poly-1 in temperature range of $140-180^{\circ} \mathrm{C}$ at $100 \mathrm{~kg} \mathrm{~cm}^{-2}$ of hydrogen pressure and $9.89 \times 10^{-2} \mathrm{mM}$ of 2 . 


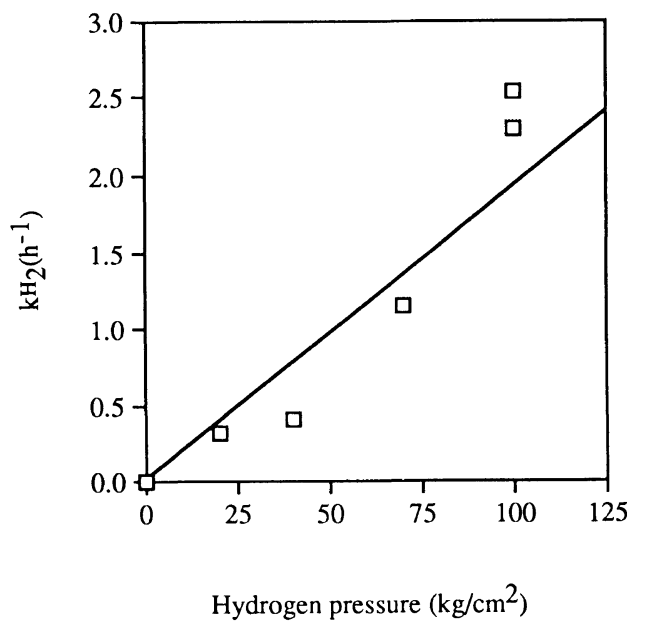

Figure 4. Effects of hydrogen pressure on the hydrogenation reaction rate at $165^{\circ} \mathrm{C}$ and $9.89 \times 10^{-2} \mathrm{mM}$ of 2 .

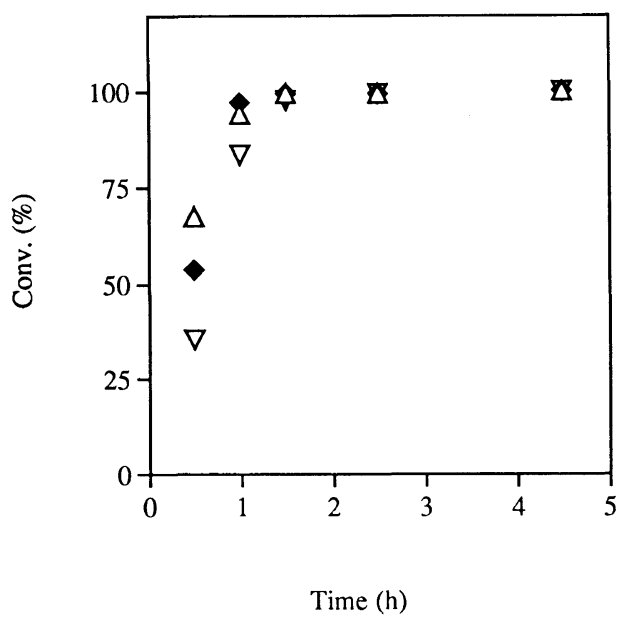

Figure 5. Time-conversion plots for entries $2-1(\triangle), 2-2(\diamond)$, and 13 $(\nabla)$. Entry 13 was carried out with slower stirring.

in Table II (entries $6-8$ ). The effect of the hydrogen pressure on the reaction rate constant is depicted in Figure 4. Plots indicate a linear relationship between hydrogen pressure and apparent hydrogenation rate. Contribution of hydrogen diffusion to the solvent to the reaction rate was excluded by the experiments with slower stirring rate (compare entry 13 and entries $2-1$ and 2-2). The time-conversion plots for entries 2-1, 2-2, and 13 are shown in Figure 5. Although the apparent reaction rates were not affected by stirring (see Table II), the conversion for entry 13 at $0.5 \mathrm{~h}$ was lower than for entries $2-1$ and $2-2$. This suggests that at the very beginning of the reaction of entry 13 , the diffusion of hydrogen into the reaction solution contributes to the reaction rate. However, after reaching the equilibrium concentration of hydrogen, the reaction seemed to follow the same kinetics as entries 2-1 and 2-2. The ambiguous relation between hydrogen pressure and the reaction rate does not seem a result from the diffusion of hydrogen into the solvent.

The effect of concentration of 2 can be evaluated by entries 9 to 12, 2-1, and 2-2. The reaction with the lowest concentration of 2 proceeded extremely slowly and was somewhat different from the simple first order kinetic. It is possible that the amount of the catalyst was too

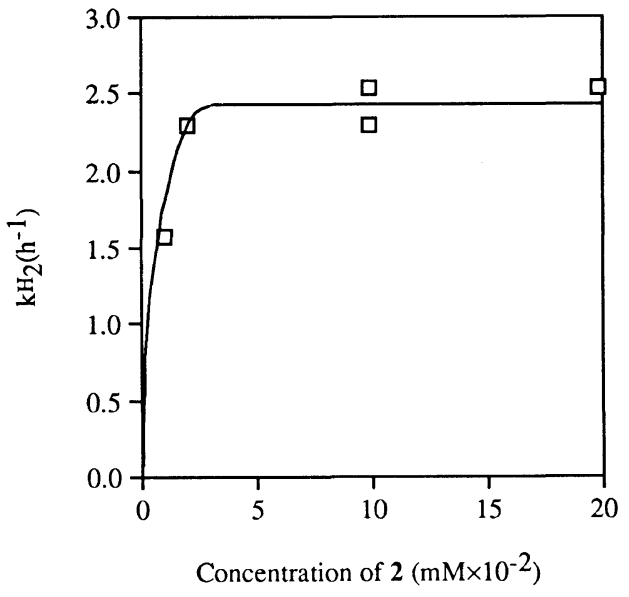

Figure 6. Effects of concentration of $\mathbf{2}$ on the hydrogenation reaction rate at $165^{\circ} \mathrm{C}$ and $100 \mathrm{~kg} \mathrm{~cm}^{-2}$ of hydrogen pressure.

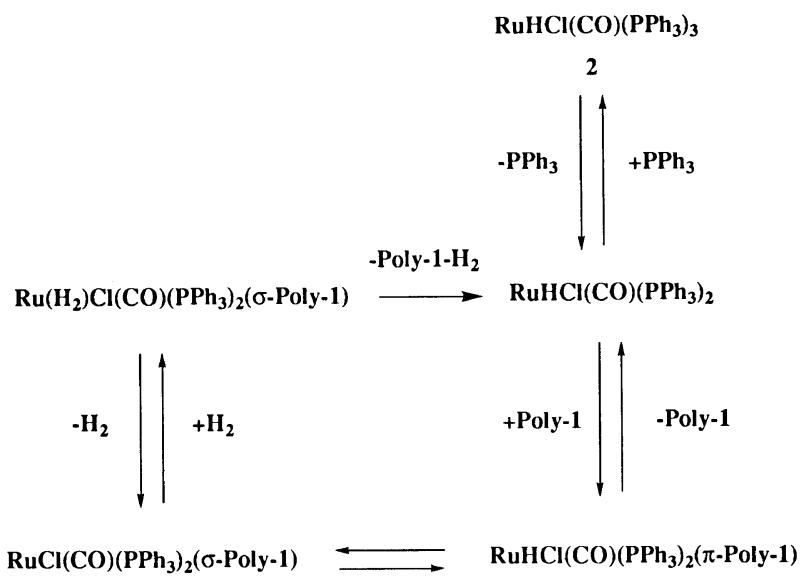

Scheme 1.

small that trace impurity could affect the reaction. Plots of reaction rate against the concentration of 2 (Figure 6) show that the reaction rate levels off at around $3 \times 10^{-2} \mathrm{mM}$ of 2 . At high concentration of 2 , the reaction follows first order kinetic respect to concentration of the double bond at constant hydrogen pressure as shown in eq 1.

$$
-\frac{\mathrm{d}[\mathrm{C}=\mathrm{C}]}{\mathrm{d} t}=k_{\mathrm{H}_{2}}[\mathrm{C}=\mathrm{C}] \quad\left(\left[\mathrm{H}_{2}\right]=\text { const }\right)
$$

The observation above seems to fit quite well with the mechanistic scheme suggested for this type of homogeneous transition metal hydrogenation catalysts. There is no detailed mechanistic study specifically on hydrogenation catalyzed by $\mathbf{2}$. The reaction mechanism for this system can be similarly drawn as for other ruthenium(II) complexes. ${ }^{25}$ The suggested mechanism is shown in Scheme 1. That notable retardation of the reaction was induced by the addition of excess amount of triphenylphosphine suggests the presence of the equilibrium between 2 and $\mathrm{RuHCl}(\mathrm{CO})\left(\mathrm{PPh}_{3}\right)_{2}$. This eliminationcoordination reaction prior to the hydrogenation catalytic cycle is well established in many cases. ${ }^{18,24,25}$ The next step is coordination of poly-1 at carbon-carbon double bond forming $\pi$-complexed species, $\mathrm{RuHCl}(\mathrm{CO})$ $\left(\mathrm{PPh}_{3}\right)_{2}(\pi$-poly-1). Hydride transfer results in $\sigma$-bonded 
complex, $\mathrm{RuCl}(\mathrm{CO})\left(\mathrm{PPh}_{3}\right)_{2}(\sigma$-poly-1). Since the reaction was first order with respect to the double bond concentration of poly-1, the hydride transfer reaction must be relatively faster than the $\pi$-complex forming reaction. Another question arising from this reaction scheme is the lack of selectivity in cis and trans double bond. Relatively vigorous reaction conditions (temperature, hydrogen pressure) could make the selectivity invisible. It is also possible that the steric hindrance to the metal center approaching perpendicular to the double bond plane do not change much for cis and trans isomers, since the double bond has a bulky tricyclic ring on both sides.

The $\sigma$-poly-1 complex undergoes hydrogen coordination reaction which is followed by regeneration of $\mathrm{RuHCl}(\mathrm{CO})\left(\mathrm{PPh}_{3}\right)_{2}$ and release of the saturated poly-1 $(\text { poly-1-H })_{2}$. When hydrogen pressure is constant, the reaction follows the first order kinetic with respect to the double bond concentration.

Overall reaction scheme is quite simple and there was no unexpected effect caused by the polymeric nature of the substrate. These results indicate that when a polymer does not have strongly coordinating group, hydrogenation with homogeneous catalysts would proceed smoothly as in the case of low molecular weight olefins.

\section{CONCLUSIONS}

High $T_{\mathrm{g}}$ ROMP of poly-1 was hydrogenated with various Ru based homogeneous hydrogenation catalysts. Hydrido- and dihydrido-complexes showed high activity realizing high turnover number and high hydrogenation degree. In the case of $\mathbf{2}$, ruthenium metal concentration to the polymer could be reduced as low as $20 \mathrm{ppm}$ providing minimal residual metals in the resultant poly1- $\mathbf{H}_{2}$. The kinetics of the hydrogenation of poly-1 with 2 followed first order with respect to the double bond concentration without any noticeable effect caused by polymeric nature. Though the reaction rate was affected at low concentration of $\mathbf{2}$, the reaction rate turned zero order at the concentration of 2 when $3 \times 10^{-2} \mathrm{mM}$ or more of 2 was used. Although poly-1 contains cis and trans double bonds, no difference in reaction rate was observed between the two structures. The homogeneous catalyst system for hydrogenation of poly-1 is useful compared to heterogeneous catalysts such as palladium.

\section{REFERENCES}

1. V. Dragutan, A. T. Balaban, and M. Dinonie, "Olefin Metathesis and Ring-Opening Polymerization of Cyclo-olefins," WileyInterscience, New York, N.Y., 1985.

2. K. J. Ivin, J. J. Rooney, L. Bencze, J. G. Hamilton, L. M. Lam, G. Lapienis, B. S. R. Reddy, and H. T. Ho, Pure Appl. Chem., 54, 447 (1982).

3. F. W. Michelotti and W. P. Keaveney, J. Polym. Sci., Part A, 3, 895 (1965).

4. R. E. Rinehart and H. P. Smith, J. Polym. Sci., Part B, 3, 1049 (1965).

5. W. Ast, G. Rheinwald, and R. Kerber, Makromol. Chem., 177, 1349 (1976).

6. R. R. Schrock, Acc. Chem. Res., 23, 158 (1990).

7. M. Schimetta and F. Stelzer, Macromolecules, 27, 3769 (1994).

8. M. G. Perrott and B. M. Novak, Macromolecules, 29, 1817 (1996).

9. V. Heroguez, S. Breunig, Y. Gnanou, and M. Fontanille, Macromolecules, 29, 4459 (1996).

10. T. M. Swanger and R. H. Grubbs, J. Am. Chem. Soc., 109, 894 (1987).

11. F. L. Klavetter and R. H. Grubbs, J. Am. Chem. Soc., 110, 7807 (1988).

12. R. Schlund, R. R. Schrock, and W. E. Crowe, J. Am. Chem. Soc., 111, 8004 (1989).

13. C. B. Gormann, E. J. Ginsberg, and R. H. Grubbs, J. Am. Chem. Soc., 115, 1397 (1993).

14. Y. Yoshida, K. Goto, and Z. Komiya, J. Appl. Polym. Sci., 66, 367 (1997).

15. B. H. Sohn, J. A. Gratt, J. K. Lee, and R. E. Cohen, J. Appl. Polym. Sci., 58, 1041 (1995).

16. J. Kodemura and T. Natusuume, Polym. J., 27, 1167 (1995).

17. A. D. Benedicto, B. M. Novak, and R. H. Grubbs, Macromolecules, 25, 5893 (1992).

18. N. A. Mohammadi and G. L. Rempel, Macromolecules, 20, 2362 (1987).

19. N. Seehof and W. Risse, Macromolecules, 26, 5971 (1993).

20. M. A. Hillmyer, W. R. Laredo, and R. H. Grubbs, Macromolecules, 28, 6311 (1995).

21. N. Ahmad, J. J. Levison, S. D. Robinson, and M. F. Uttley, Inorg. Synth., 15, 45 (1974).

22. S. D. Robinson and M. F. Uttley, J. Chem. Soc., Dalton Trans., 1912 (1973).

23. P. S. Hallman, D. Evans, J. A. Osborn, and G. Wilkinson, Chem. Commun., 305, (1967).

24. A. J. Birch and D. H. Williamson, Org. React., 24, 1 (1976).

25. D. R. Fahey, J. Org. Chem., 38, 3343 (1973). 